\section{salmon (Salmo salar)}

Elina Halttunen ${ }^{\mathrm{a}}$, Jenny Lovisa Alexandra Jensen ${ }^{\mathrm{a}}$, Tor Fredrik Næsje ${ }^{\mathrm{b}}$, Jan Grimsrud Davidsen $^{\mathrm{a}, \mathrm{c}}$, Eva Bonsak Thorstad ${ }^{\mathrm{a}, \mathrm{b}}$, Cedar Marget Chittenden ${ }^{\mathrm{a}}$, Sandra Hamel ${ }^{\mathrm{a}}$, Raul Primicerio $^{\mathrm{a}}$, Audun Håvard Rikardsen ${ }^{\mathrm{a}}$

7

${ }^{a}$ Department of Arctic and Marine Biology, Faculty of Biosciences, Fisheries and Economics, University of Tromsø, NO-9037 Tromsø, Norway

${ }^{\mathrm{b}}$ Norwegian Institute for Nature Research, NO-7485 Trondheim, Norway

${ }_{-}^{\mathrm{c}}$ Museum of Natural History and Archaeology, Norwegian University of Science and Technology, NO-7491 Trondheim, Norway.

Corresponding author: Elina Halttunen. Tel.: +47 776460 20; fax.: +47 776208 53; e-mail address: elina.halttunen@uit.no

6 E-mail addresses of co-authors: jenny.jensen@uit.no, tor.naesje@nina.no,

7 jan.davidsen@ntnu.no, eva.thorstad@nina.no, cedar.m.chittenden@uit.no,

8 sandra.hamel@uit.no, raul.primicerio@uit.no, audun.rikardsen@uit.no

9




\section{Abstract}

25 Atlantic salmon (Salmo salar) often survive spawning and migrate back to the sea to feed,

26 either shortly after spawning in autumn or in the following spring. We conducted a four-year

27 observational field study using telemetry to evaluate the determinants of migration timing in

28 Atlantic salmon post-spawners (kelts). We found that individuals with low energy reserves

29 migrated early to the risky but productive marine habitat, whereas individuals with greater

30 energy reserves stayed in the safe but less productive river habitat until staying became

31 energetically more costly than migrating. For males, the likelihood of overwintering in the

32 river instead of migrating in autumn increased 27-fold with each increase in body condition

33 index, whereas almost all females overwintered in the river. Among spring migrants, body

34 condition was the strongest determinant of migration timing, and females left the river about

35 five days later than males. Our study suggests that migration timing in Atlantic salmon kelts

36 is the outcome of adaptive state-dependent habitat use, related to individual and sexual

37 differences in energy allocation during spawning.

38

39 Keywords: telemetry, life-history, reproduction, iteroparity, behaviour 


\section{Introduction}

42 Anadromous salmonids reproduce in fresh water, but achieve the bulk of their growth at sea

43 (Gross 1987). The marine part of the lifecycle is generally characterised by low survival and

44 rapid growth, whereas the freshwater residency offers poorer growth (Jonsson and Jonsson

45 1993). This difference exists because both the predation pressure and production are higher in

46 the marine than in the freshwater habitat (Gross 1987; Ward and Hvidsten 2010). As

47 salmonids are ectotherms, they also grow faster with increasing temperature up to a growth

48 optimum (Jobling 1994, Jobling et al. 2010). Therefore, salmonids grow especially well in

49 the summer when both the temperature and the food availability are high at sea (Ingvaldsen

50 and Loeng 2009; Rikardsen and Dempson 2010).

51 In contrast to most Pacific salmon species, Atlantic salmon (Salmo salar L.1758) often survive spawning in the river (Jonsson et al. 1990; 1991a), and perform repeated marine feeding migrations to build new reserves for re-occurring spawning events (Fleming 1996). The low temperatures experienced by the surviving post-spawning salmonids after spawning

55 (late autumn/winter) restrict their activity and growth potential (see Knutsen et al. 2004) both in the river and at sea. Therefore, the winter season is not ideal for re-building depleted energy resources. This may explain the large individual variation in the timing of feeding migration observed in post-spawning Atlantic salmon (kelts); they either migrate shortly after spawning in the autumn, or during the following spring/summer (Jonsson et al. 1990; 1991a; Niemelä et al. 2000; Webb et al. 2007).

Here, we hypothesize that the variation in migration timing is the outcome of adaptive statedependent habitat use, related to differences in energy allocation during spawning. In order to address this hypothesis, we analysed data from a four-year observational field study based on remote sensing of individual behaviour. We tagged a total of 352 Atlantic salmon, and 
registered their post-spawning freshwater survival and migratory timing by means of acoustic and radio telemetry. For Atlantic salmon, the likelihood of repeat spawning is negatively related to energy depletion during the previous spawning event (Fleming 1996). The assetprotection principle (Clark 1994) predicts that individuals with low energy reserves and a low probability of future reproduction should accept risky, productive habitats, whereas individuals with large reserves and a high probability of future reproduction should choose safe but less productive habitats. Therefore, applying the asset-protection principle to the migration of Atlantic salmon kelts, we predicted that kelts with low energy reserves would migrate to the sea shortly after spawning, whereas kelts with larger reserves would stay in the

74 river until reaching an energetic threshold, determined by a trade-off between metabolic costs and gains in fresh waters versus marine waters. We thus expected the migration timing to be governed by individual factors related to state-dependency, specifically the individual's body condition, size and sex. As large Atlantic salmon individuals tend to allocate relatively more energy to spawning than small individuals (Jonsson et al. 1997), and as males have higher energy expenditure than females (Jonsson et al. 1991b; Fleming et al. 1997; Niemelä et al. 2000), we expected that (i) individuals in poor body condition would leave the river early, (ii) males would leave the river earlier than females, and (iii) large individuals would leave the river earlier than small individuals. 


\section{Study area}

86

87

88

89

90

91

92

93

94 monitoring movements of individual fish by using electronic tags that transmit individually

107

The study was conducted in Alta River and Fjord in northern Norway $\left(70^{\circ} \mathrm{N}, 23^{\circ} \mathrm{E}\right.$, Fig. 1) during 2007-2010. Alta River has a catchment area of $7400 \mathrm{~km}^{2}$ and a mean annual water discharge of $75 \mathrm{~m}^{3} \mathrm{~s}^{-1}$. It supports a large Atlantic salmon population with annual in-river catches between 6 and $32 \mathrm{t}$, with a mean mass of $5.2 \mathrm{~kg}$ for individual Atlantic salmon (Ugedal et al. 2008). Most spawners spend one or three years in the sea, where one-seawinter fish (1SW) are mainly males (76\%, mean $2.3 \mathrm{~kg})$ and three-sea-winter fish (3SW) are mainly females $(77 \%$, mean $10.0 \mathrm{~kg}$ ) (Ugedal et al. 2008). Repeat spawning is more common in females than in males, and the large majority of both female and male repeat spawners spend one year at sea before returning to spawn again (Halttunen et al. 2011). The river length accessible to Atlantic salmon is $46 \mathrm{~km}$, and a hydropower plant was constructed above this stretch in 1987. Winter freeze-up usually occurs in November, and spring ice break-up normally occurs in early May. There are numerous suitable areas for kelts to overwinter (deep pools, still waters), and a minimum discharge of $20-30 \mathrm{~m}^{3} \mathrm{~s}^{-1}$ is maintained by the hydropower plant during the winter. The peak spawning run of Atlantic salmon occurs from mid-June through July, and spawning commences during the first half of October (Ugedal et al. 2008).

\section{Tagging}

The post spawning survival and seaward-migration timing of Atlantic salmon kelts was assessed by the use of radio and acoustic telemetry (Cooke et al. 2004). Both methods enable coded signals. Radio telemetry was used to assess the post-spawning survival and the overall 
131 One-sea-winter Atlantic salmon often escape bag nets due to the large mesh sizes. Therefore, 132 the radio-tagged group was biased towards MSW males, and so the radio-tagged group was

seaward-migration timing of kelts. The method was chosen because it enabled tracking of fish through ice during the winter. Acoustic telemetry was used for a higher resolution study of out-migration timing versus energy reserves in the spring. The method was chosen because it enables tracking fish in saline water.

\section{Radio tagging}

We tagged a total of 166 returning Atlantic salmon in the Alta Fjord and River between June and September 2008-2009 (Table 1). Multi-sea-winter (MSW) fish (56 males, 2-5SW, mean fork length $95 \mathrm{~cm}$; 92 females, 2-6SW, mean fork length $94 \mathrm{~cm}$ ) were captured in bag nets in the Alta Fjord during their spawning migration towards the Alta River from June to August 2008-2009. Uninjured specimens were placed in a $400 \mathrm{~L}$ tank with oxygenated water in the research vessel (time in tank 5-120 min), and thereafter externally tagged with radio transmitters (Model F2120, Advanced Telemetry Systems (ATS), MN, flat with outline dimensions $21 \times 52 \times 11 \mathrm{~mm}$, mass in air $15 \mathrm{~g}$, estimated battery lifetime 10 or 13 months). Individuals could be identified by using unique combinations of frequencies and pulse-rates. The fish were anaesthetised prior to tagging (2-phenoxy-ethanol, EC No. 204-589-7, SIGMA Chemical Co., MO, $0.5 \mathrm{ml} \mathrm{L}^{-1}$, mean time $2 \mathrm{~min} 40 \mathrm{sec}$ ), and thereafter placed in a waterfilled tube with the head and gills submerged. The radio transmitters were attached through the musculature $3-4 \mathrm{~cm}$ below the dorsal fin by use of $0.8 \mathrm{~mm}$ stainless-steel wires, and anchored to a $10 \times 40 \mathrm{~mm}$ plastic back plate. The mean tagging time was $1 \mathrm{~min} 50 \mathrm{sec}$, and the mean handling time was 5 min $20 \mathrm{sec}$. The tagged fish were left to recover in the oxygenated tank under observation (mean time $2 \mathrm{~min} 50 \mathrm{sec}$ ), whereupon they were released back into the fjord to resume their migration towards the river. 
133 more similar in size than the acoustically tagged group (see Table 1). To increase the number

134 of $1 \mathrm{SW}$ males in the study, eight additional individuals (mean fork length $57 \mathrm{~cm}$ ) were

135 captured by rod and reel in the upper parts of the river between 6 and 30 September 2009,

136 and tagged using similar procedures as described above. An additional 10 MSW Atlantic

137 salmon (eight females, two males, mean fork length $92 \mathrm{~cm}$,) were captured in the same area

138 and tagged during the same period (Table 1).

139

140 Acoustic tagging

141 We tagged a total of 202 kelts (57 males, 1-3SW, mean fork length $65 \mathrm{~cm}$; 145 females, 2-

142 7SW, mean fork length $94 \mathrm{~cm}$, Table 1) with acoustic tags (Vemco Inc., Canada, model V13-

$1431 \mathrm{~L}$, cylindrical with dimensions $13 \mathrm{~mm} \times 36 \mathrm{~mm}$, mass in air $11 \mathrm{~g}$, and Thelma AS, Norway, 144 model MP-13, $13 \mathrm{~mm} \times 31 \mathrm{~mm}$, mass in air $11 \mathrm{~g}$, estimated battery life 13 or 37 months) in the 145 Alta River during April - May 2007-2009. The kelts were captured in the river by angling 146 with barbless treble hooks, anaesthetised and tagged internally according to Halttunen et al. 147 (2010). All kelts were also externally tagged with modified Carlin tags with contact and 148 reward information for the report of recaptures.

Tracking

$151 \quad$ Radio tracking

152 To detect radio-tagged fish descending the river, automatic stationary receivers storing

153 information on tag ID and time of registration (R4500S Scientific receiver, ATS, connected 154 to a four- or nine-element Yagi-antenna) were installed 1 and $8 \mathrm{~km}$ upstream from the river 155 outlet during both study years (Fig. 1). In addition, stationary receivers were operative 15 and $15619 \mathrm{~km}$ upstream from mid-October 2009. The scan time on the receiver for each frequency 
used on radio transmitters was $5 \mathrm{sec}$, giving a total scan time ranging from $2 \mathrm{~min} 30 \mathrm{sec}$ to 4

$158 \min 10 \mathrm{sec}$ to cover all frequencies used and to be able to register fish within the detection 159 area of the receiver (approximately $1 \mathrm{~km}$ ).

161 The positions and possible predation events of the radio-tagged fish within the river were 162 determined by manual tracking using a portable receiver (R410 Scanning receiver, ATS, 163 connected to a three-element Yagi-antenna). The fish were positioned with an accuracy of 164 approximately $\pm 300 \mathrm{~m}$, i.e. fish were localized to a specific pool in the river. Tracking was performed approximately every second week from spawning (October) until the river froze ( $\sim$ mid-November), on a monthly basis during winter, and every third week from ice break-up

167 ( mid-April) until the end of July. Due to unstable ice conditions during the winter 20081682009 , tracking in December and January could not be performed because accessing these 169 remote areas in wintertime requires snowmobile transport on the river ice.

\section{Acoustic tracking}

172 To detect acoustically tagged fish descending the river, eleven acoustic receivers (model

173 VR2, Vemco Inc.) were deployed at $5 \mathrm{~m}$ depth, spaced $400 \mathrm{~m}$ apart, in an array across the 174 Alta Fjord 4 km from river mouth (Fig. 1) between April and October 2007-2009. In addition, 175 two receivers were deployed near the river mouth in the lower reaches of the river.

176 Information on the time of registration and the tag ID were stored in the acoustic receivers 177 whenever an individual passed within the detection range. The receivers were able to detect 178 fish at a range varying from 200-600 m, depending on environmental conditions. Hence, all 179 fish passing the receiver arrays were within the detection range. 


\section{Sampling}

182 A total of 144 kelts (46 males and 68 females, mean fork length $82 \mathrm{~cm}$, range $50-112 \mathrm{~cm}$ ) were sacrificed during tagging in the river (2007-2009), and their stomach contents were analysed. The water temperature and discharge in the river were measured hourly at Kista hydrographical station $28 \mathrm{~km}$ upriver, and the sea temperature was measured at an average of 10 days interval at Ingøy hydrographical station ( $\left.\mathrm{N} 71^{\circ} 08^{\prime} \mathrm{E} 24^{\circ} 01^{\prime}\right)$ at one meter depth.

\section{Data analysis}

\section{The minimum survival of Atlantic salmon kelts}

190 Because we chose small tags to minimize potential tag effects on behaviour (Thorstad et al. 191 2000), some of the batteries were dead before the fish left the river. Due to the uncertain fates

192 of fish with undetected exit, we based the survival rate estimate strictly on confirmed survived fish, i.e. fish with detected exit and recaptured fish, and therefore our survival estimate is a minimum estimate. We considered fish reported recaptured and released by anglers in the river during 1 June - 31 August to be alive with a high survival probability,

196 despite being caught and released (Halttunen et al. 2010). Predation was assessed from 197 tagged carcasses detected in the vicinity of the river.

200 Two separate models were used to test the determinants for the timing of seaward-migration; 201 a logistic regression model to assess the probability of the radio-tagged fish migrating either during autumn (defined here as before end of January) or spring (defined her as after onset of

203 April), and a linear regression model to explain sea entry date (in Julian days using 1 May as 204 day 1) of the acoustically tagged fish in the spring. For both analyses, we were interested in 
assessing the influence of sex, length (fork length in $\mathrm{cm}$ ), body condition index and their interactions. The body condition index consisted of the residuals of log [mass] regressed on $\log$ [length], and was chosen in order to avoid co-linearity between the explanatory variables length and body condition $(R=0.34)$. The body condition index was calculated from length and mass measured at tagging, i.e. it represented the body condition in two distinct phases of the spawning migration; before spawning for the radio tagged fish and after spawning and overwintering for acoustically tagged fish. The variable year was included to account for among-year variation in the environment, which can be considerable; for example, the timing and intensity of the flood peak varied greatly among the study years (range $400-816 \mathrm{~m}^{3} \mathrm{~s}^{-1}$,

214 Fig. 2). The variable tag site was included as a covariate in the linear model explaining sea entry date to control for distances between tagging sites and the sea.

216 For the logistic regression model predicting spring migration, only 2 females out of 63 left in 217 autumn (3\%) compared with 9 out of 21 males (43\%). Therefore, we only analysed the 218 probability of spring migration for males. Because we had very few males in this analysis, we 219 could not assess the influence of interactions. In addition, to prevent type II errors owing to 220 the low power of the test (4 estimates -intercept, year, condition, length- for 21 data points), 221 we performed stepwise removal of least significant variables. We performed a Pearson $\chi^{2}$ 222 statistic to assess the goodness-of-fit of the model, which showed no evidence of over223 dispersion $(P=0.99)$. We present odds ratio (with 95\% confidence intervals), which is a 224 measure of effect size in logistic regression (Nakagawa and Cuthill 2007). For continuous 225 variables like length and body condition index, the odds ratio is the odds of migration 226 occurring in the spring with an increase of one unit, e.g. the ratio of the odds when length 227 equals $100 \mathrm{~cm}$ to the odds of it occurring when it equals $101 \mathrm{~cm}$. An odds ratio of 1 indicates 228 that spring migration is equally probable with change of one unit. When the ratio moves 229 towards 0 , spring migration is more likely to occur with a decrease of one unit, whereas when 
230 it moves towards infinity, it is more likely to occur with an increase of one unit. To assess the

231 performance of the logistic model, we report the area under the receiver operating

232 characteristic curve (AUC), which measures the overall predictive accuracy of the model

233 independent of a specific threshold (Fielding and Bell 1997, R package "lrm"). AUC values

234 vary from 0.5 to 1 , and represent the percentage of randomly drawn pairs (i.e. one of each

235 group) that the model classifies correctly. Generally, the predictive accuracy of a model is

236 classified as "worthless" with an AUC close to 0.5 and "excellent" with an AUC close to 1.0.

237 All variables in both models were centred to allow interpretation of main effects

238 independently of interactions (Schielzeth 2010). In addition, all continuous variables were

239 standardized in order to provide standardized parameter estimates that allow comparing the

240 magnitude of the effects, and hence, the importance of each variable (Schielzeth 2010).

241 Because the models included a categorical variable, we used two standard deviations to

242 standardize the continuous variables, therefore permitting comparison between categorical

243 and continuous variables (Gelman 2008; Schielzeth 2010). All statistical analyses were

244 conducted using the open source $\mathrm{R}$ language for statistical computing and graphics ( $\mathrm{R}$

245 Development Core Team 2009). 
247 The minimum survival of Atlantic salmon kelts

248 The minimum survival of Atlantic salmon kelts was 63\% (98/156 individuals included in the

249 analysis, both study years pooled). Out of these survivors, 13\% (13/98) left the river in the 250 autumn, and the remaining $87 \%(85 / 98)$ left in the spring. The majority of the autumn 251 migrants (10 of 13, 77\%) were MSW males. The minimum survival rate was higher for MSW 252 females $(74 \%)$ than for MSW males $\left(43 \% ; \chi^{2}\right.$-test, $\left.P<0.001\right)$, but there was no difference in 253 survival between MSW females and 1SW males (62\%; Fisher's exact test, $P=0.70)$.

\section{Overall seaward-migration timing of Atlantic salmon kelts}

256 Despite no difference in the body condition between the males and females ( $t$ test assuming 257 equal variances: $t=1.99, P=0.29, \mathrm{df}=80$ ) upon entry, almost all females started their 258 migration in spring (97\%) whereas almost half of the males migrated in the autumn (43\%).

259 Even though salmons had a slight tendency to enter later with lower body condition (Pearson 260 correlation coefficient: $r=-0.20, P=0.08, \mathrm{n}=76$ ), the river entry date was not correlate with 261 the exit date (Pearson correlation coefficient: $r=-0.05, P=0.69$ ). Among males, the 262 complete model (with low power because it is getting towards saturation with about 5 data 263 points available for each estimate) showed a tendency for males in better condition to leave in 264 the spring (Table 2). Model reduction, increasing the power of the analysis, confirmed the 265 effect of condition on the probability of spring migration (odds ratio $[\mathrm{CI}]=26.7[2.2 ; 1265.0]$, 266 Wald $\chi^{2}=2.1, P=0.036$ ). Males were 27 times more likely to migrate in the spring with each 267 increase of one unit in body condition index (Fig. 3). In general, the probability of males migrating to sea in the spring was $50 \%$ if their body condition index was close to 0 or 
positive, meaning fish of average or higher than average condition (Fig. 3). Overall, the model had an excellent predictive power, as indicated by the high AUC value (Table 2).

Migration timing among spring migrating Atlantic salmon kelts

273 In total, $188(93 \%)$ of all the acoustically-tagged spring migrants were detected on the

274 acoustic arrays in the fjord. Among sex, body condition, and fork length, body condition had

275 the strongest influence on migration timing of detected fish: fish in better body condition

276 migrated later, and this effect was stronger for females than for males (Table 3, Fig. 4a). Sex

277 was the second strongest predictor but its effect was three times smaller than that of body

278 condition (Table 3). On average, females migrated five days later than males (Table 3). Fish

279 length did not affect sea entry date in the spring, but its interaction with sex was a strong

280 predictor (Table 3, Fig. 4b); males entered the sea slightly later with increasing fork length,

281 whereas females' sea entry date did not vary with length. Sea entry date varied among years, 282 but variation among tag sites was negligible (Table 3). The median migration date during the 283 study period was 9 June (Fig. 2).

\section{River and sea temperatures, feeding and predation in the river}

286 The river winter temperatures (1 November - 30 April) in 2007-2010 ranged between 0.0$2873.0^{\circ} \mathrm{C}$ (average of $0.4^{\circ} \mathrm{C}$ ), while the sea temperatures ranged between $4.1-7.8^{\circ} \mathrm{C}$ (average of $2885.6^{\circ} \mathrm{C}$ ). The river temperatures surpassed the sea temperatures each year in the middle of June 289 (Fig 2). None of the sampled kelts had stomach contents, and we observed no predation on 290 the tagged fish. 


\section{Discussion}

292 Consistent with our expectations, fish in poorer condition left the river earlier than fish in

293 better condition, both when comparing between autumn and spring migrating males, and 294 among spring migrating females and males. This indicates that there may be an inherent 295 advantage to prolonging the freshwater residency instead of initiating the seaward-migration as soon as possible. We suggest that the advantage may be related to the differences between

297 the river and marine habitat during winter, in relation to metabolic costs vs. gains, and

298 predation risk. The river is a low-cost, low-gain, and low-risk habitat for overwintering kelts.

299 Fish that overwinter in the river at temperatures close to $0{ }^{\circ} \mathrm{C}$ should have very low metabolic costs (Jobling 1994). We found no evidence for metabolic gains through feeding (because kelts had empty stomachs), and the kelts risk little or no predation in the river, as they are virtually untouchable under the protective ice cover. The known predators of Atlantic salmon

303 in the River Alta are white-tailed sea eagles Haliaeetus albicilla and European otters Lutra 304 lutra, and as a rule, they feed on dead fish after spawning before the river freezes (E. Halttunen, personal observations). The marine environment, on the other hand, is a productive but more risky habitat for kelts. Despite lower marine production during winter,

307 there are prey (fish, amphipods, euphausiids) available in the sea throughout the year. In

308 addition, even though marine predation on adult Atlantic salmon is not considered an 309 important factor for mortality (reviewed by Mather 1998), large predators like seals and 310 whales are known to predate upon adult salmon (Ward and Hvidsten 2011, own unpublished 311 data). Therefore, we suggest that individuals that can energetically afford to do so, should 312 overwinter in the river and migrate to the sea when increased temperatures improve feeding 313 opportunities. This hypothesis is further supported by the fact that the median outmigration 314 date among the spring migrants coincided roughly with the equalising of temperatures in the river and along the outer coast, therefore rendering the metabolic costs of staying in the river 
316 higher than that of migrating to the sea. As Atlantic salmon migrate between the river and

317 marine habitats, where they cover large distances (Klemetsen et al. 2003), optimizing each

318 leg of the migration to the lowest possible risk and the highest possible gain is likely

319 important for the overall survival and lifetime fitness.

321 Consistent with our expectations, males left the river earlier than females, both when 322 comparing autumn to spring migrants and spring migrants among each other. Atlantic salmon 323 males generally invest more of their somatic energy (36\%) in spawning than females (25\%, 324 Jonsson et al. 1991b) as a result of active and aggressive behaviour and investments in 325 secondary sexual traits (Fleming 1998). This somatic energy loss, when added to injuries 326 acquired during intense male-male competition during spawning, may lead to poor 327 physiological status and high post-spawning mortality among males (Jonsson et al. 1990;

328 Baglinière et al. 1991; Fleming 1998). However, Atlantic salmon males display two 329 alternative reproductive strategies. They return from their sea feeding migration either after 330 one winter as small individuals, or after multiple winters as large individuals. Small males 331 invest less of their total energy in spawning (40-50\%) compared to large males (up to 70\%), 332 and larger males fight more violently (Fleming 1996; Jonsson et al. 1997; Jonsson and 333 Jonsson 2003). Accordingly, the mortality among large males in this study was higher than 334 among females and small males, and almost all of the autumn migrants were large males.

335 Small males may minimize their involvement in the spawning event to conserve their energy, 336 therefore increasing their chances of surviving to spawn again (Seamons and Quinn 2010).

337 This seems to be the case in River Alta, where small males have a much higher repeat spawning probability than large males (Halttunen 2011). 
340 Almost all females (98\%) overwintered in the river and started their ocean migration in the

341 spring, despite large variations in body condition when entering the river. This shows a clear

342 difference in the overall migration strategy between the sexes, and most likely, a difference in

343 energy allocation during spawning. Atlantic salmon females generally allocate most of their

344 energy reserves in egg production ( 30\%; Jonsson and Jonsson 2003$)$ and little in aggression

345 and competition, therefore suffering lower post-spawning mortality (Jonsson et al 1990;

346 Baglinière et al. 1990, 1991; Fleming 1998). Consequently, females have a higher repeat-

347 spawning probability than males (Heggberget 1989; Jonsson et al. 1990; Niemelä et al. 2000).

348 Females in River Alta can spawn multiple times (Halttunen 2011). Therefore, according to

349 the asset protection principle (Clark 1994), females should choose safe but less productive

350 habitats like the river after spawning, and hence prioritise the next spawning occasion

351 because they have a high future reproductive probability. As the large majority of the repeat

352 spawning females and males spend a year in the sea before returning, i.e. spawn alternate

353 years (Halttunen 2011), the difference in the migration behaviour between sexes cannot result

354 from a difference in repeat spawning.

355

356 Based on the knowledge that larger fish tend to use more energy than small fish during

357 spawning (Jonsson et al. 1997), we expected large individuals to leave the river earlier than

358 small individuals, and this was certainly true for the overall migration pattern of males, where

359 almost all of the autumn migrants were large males. However, we observed the contrary

360 among the spring migrating males; larger males left the river at a later date than smaller

361 males (Fig 4b). For spring migrating females, length had no effect on migration timing (Fig

$3624 b)$. There might be several factors accounting for large size not advancing the outmigration

363 date in the spring. Especially for females, large size is an asset worth protecting, as size

364 correlates positively with fecundity (Fleming 1996). Large fish also have a lower metabolic 
rate in relation to body size than small fish (Jobling 1994), and might use relatively less energy than small fish during overwintering. In addition, large fish might be more dependent

367 on good feeding conditions to meet the demands of growth compensation. Growth compensation (Jobling 1994, 2010; Ali et al. 2003) is a phenomenon occurring in Atlantic salmon after a period of starvation, induced by the loss of body mass and reduced lipid reserves. It leads to high feeding rates, and a growth rate above that normally recorded in fish that feed regularly. Growth compensation may have far-reaching consequences, as there are trade-offs between growth and other fitness-related traits, such as physiological costs in the

373 form of reduced swimming performance, immune capacity and developmental stability

374 (Jobling 2010; Ali et al. 2003). Therefore, waiting for good growth conditions before starting the feeding migration might be crucial for adult post-spawners, and especially for large ones.

377 Variation among years affected the overall (autumn/spring) migration timing of Atlantic 378 salmon kelts, likely due to annual changes in environmental factors. The river temperatures 379 Atlantic salmon experience prior to and during spawning will have an immediate effect on 380 their energy expenditure through metabolic costs (Jobling 1994). As we suggest that out381 migration is related to body condition, this could explain the differences between years in the 382 likelihood of migrating in the autumn. Environmental factors had also a significant effect on 383 the out-migration during spring. The migration timing of kelts varied in accordance to the 384 timing of the flood peak (earliest in 2009 and latest in 2008, Table 3, Fig. 2), and hence the 385 spring flood may be an important environmental cue for kelt migration initiation. This 386 concurs with the migratory timing of Atlantic salmon smolts, which synchronize their out387 migration with environmental cues in an attempt to match the most profitable growth 388 conditions at sea (Hvidsten et al. 2009; Rikardsen and Dempson 2010). However, despite the 389 clear effect of environmental cues, the out-migration of kelts spanned out over a period of 6- 
39012 weeks, whereas the smolts migrate over a more concentrated time period (Jensen et al.

391 2012). This might be because kelts are considerably larger than smolts, and therefore not

392 dependent on the safety of a crowd under migration. Also, kelts have larger mouths, and

393 therefore, a larger feeding repertoire than smolts, whereas smolts are dependent on certain

394 seasonal prey types (e.g. zooplankton; Hvidsten et al. 2009; Rikardsen and Dempson 2010).

395 Finally, even though kelts might also benefit from entering the sea in the most productive 396 season, they might be forced to leave the river earlier than would be optimal for feeding 397 opportunities at sea due to poor body condition.

398

399 On a more general note, the morphology and hydrography of rivers can play an important 400 role in the migration timing of post-spawning Atlantic salmon. The decision to overwinter in

401 the river is likely dependent on suitable overwintering areas and adequate water discharge

402 throughout the winter (as documented in e.g. brown trout Salmo trutta and Arctic charr

403 Salvelinus alpinus; Olsen et al. 2006; Jensen and Rikardsen 2012), as well as on a favourable 404 temperature regime and relative differences between river and sea temperatures. Therefore, 405 the individual condition and the future reproductive prospects of the fish work most likely in 406 concert with environmental factors in determining the overall migration timing of spent 407 Atlantic salmon. This study, however, demonstrates the importance of physical condition in 408 migration timing, and provides a theoretical framework for future salmonid migration studies.

\section{Acknowledgements}

411 Members of Alta Laksefiskeri Interessentskap (ALI), Birger Hansen and the Arild family, 412 Amund Suhr, Endre Baltesgard, Sigurd Tønnessen, Brødrene Mathisen Sagbruk og Trelast 413 DS, and the crew of FF Johan Ruud are thanked for their help during fieldwork, Gunnel 
414 Østborg is thanked for scale sample analysis, and Karl Ø Gjelland, Ola Ugedal and Michael

415 Greenachre are thanked for comments on data-analysis. The University of Tromsø,

416 Sparebanken Nord-Norge, the Norwegian Research Council, the Norwegian Institute for

417 Nature Research, the Norwegian Directorate for Nature Management, ALI, the County

418 Governor of Finnmark and Fiskeriforskningsfondet are acknowledged for funding of the

419 project. Hydrological data were provided by the Norwegian Water Resources and Energy

420 Directorate and Institute of Marine Research. All the experimental procedures were approved

421 by the Norwegian Animal Research Authority.

422 


\section{References}

424 Ali, M., Nicieza, A., and Wootton, R. J. 2003. Compensatory growth in fishes: a response to growth depression. Fish Fish. 4: 147-190. doi: 10.1046/j.1467-2979.2003.00120.x.

426

427

428

429

430

431

432

433

434

435

436

437

438

439

440

441

Baglinière, J.L., Maisse, G., and Nihouarn, A. 1990. Migratory and reproductive behaviour of female adult Atlantic salmon, Salmo salar L., in a spawning stream. J. Fish Biol. 36(4): 511-520. doi:10.1111/j.1095-8649.1990.tb03553.x.

Baglinière, J.L., Maisse, G., and Nihouarn, A. 1991. Radio-tracking of male adult Atlantic salmon, Salmo salar L., during the last phase of spawning migration in a spawning stream (Brittany, France). Aquat. Living Resour. 4(3): 161-167. doi: 10.1051/alr:1991017.

Clark, C.W. 1994. Antipredator behavior and the asset-protection principle. Behav. Ecol. 5(2): 159-170. doi:10.1093/beheco/5.2.159.

Cooke S.J., Hinch S.G., Wikelski M., Andrews R.D., Kuchel L.J., Wolcott T.G., Butler P.J. 2004. Biotelemetry: a mechanistic approach to ecology. Trends Ecol. Evol. 19(6): 334-343. doi: 10.1016/j.tree.2004.04.003.

Fielding, A.H., and Bell, J.F. 1997. A review of methods for the assessment of prediction errors in conservation presence/absence models. Environ. Conserv. 24(1): 38-49. doi: $10.1017 / \mathrm{S} 0376892997000088$.

Fleming I.A, 1996. Reproductive strategies of Atlantic salmon: ecology and evolution. Rev. Fish Biol. Fish. 6: 379-416. doi: 10.1007/BF00164323.

Fleming, I.A. 1998. Pattern and variability in the breeding system of Atlantic salmon (Salmo salar), with comparisons to other salmonids. Can. J. Fish. Aquat. Sci. 55(Suppl. 1): 59-76. doi: 10.1139/d98-009. 
446 Fleming, I.A., Lamberg, A., and Jonsson, B. 1997. Effects of early experience on the reproductive performance of Atlantic salmon. Behav. Ecol. 8(5): 470-480. doi: 10.1093/beheco/8.5.470.

Gelman, A. 2008. Scaling regression inputs by dividing by two standard deviations. Statist. Med. 27: 2865-2873. doi:10.1002/sim.3107.

Gross, M.R. 1987. Evolution of diadromy in fishes. Am. Fish. Soc. Symp. 1: 14-25.

Halttunen, E., Rikardsen, A.H., Thorstad, E.B., Naesje, T.F., Jensen, J.L.A., and Aas, Ø. 2010. Impact of catch-and-release practices on behavior and mortality of Atlantic salmon (Salmo salar L.) kelts. Fish. Res. 105(3): 141-147. doi: 10.1016/j.fishres.2010.03.017.

Halttunen, E. 2011. Staying alive - the survival and importance of Atlantic salmon postspawners. Ph.D. thesis, University of Tromsø, Tromsø, Norway. Munin Open Research Archive: http://munin.uit.no/handle/10037/3536

Heggberget, T.G. 1989. The population structure and migration system of Atlantic salmon, Salmo salar, in the River Alta, North Norway. A summary of the studies 1981-1986. In Proceedings of the Salmonid Migration and Distribution Symposium. Edited by E.L. Brannon and B. Jonsson. University of Washington, School of Fisheries, Seattle. pp. 124-139.

Hvidsten, N.A., Jensen, A.J., Rikardsen, A.H., Finstad, B., Aure, J., Stefansson, S., Fiske, P., and Johnsen, B.O. 2009. Influence of sea temperature and initial marine feeding on survival of Atlantic salmon Salmo salar post-smolts from the Rivers Orkla and Hals, Norway. J. Fish Biol. 74(7): 1532-1548. doi: 10.1111/j.1095-8649.2009.02219.x. 
469

470

471

472

473

474

475

476

477

478

479

480

481

482

483

484

485

486

487

488

489

490

491

492

Ingvaldsen, R., and Loeng, H. 2009. Physical oceanography. In Ecosystem Baretns Sea. Edited by E. Sakshaug, G. Johnsen and K. Kovacs. Tapir Academic Press, Trondheim, Norway. pp. 33-64.

Jensen, A.J., Finstad, B., Fiske, P., Hvidsten, N.A., Rikardsen, A.H., and Saksgård, L. 2012. Timing of smolt migration in sympatric populations of Atlantic salmon (Salmo salar), brown trout (Salmo trutta), and Arctic charr (Salvelinus alpinus) Can. J. Fish. Aquat. Sci. 69: 711-723. doi:10.1139/F2012-005.

Jensen, J.L.A., and Rikardsen, A.H. 2012. Archival tags reveal that Arctic charr Salvelinus alpinus and brown trout Salmo trutta can use estuarine and marine waters during winter. J. Fish Bio. 81(2), 735-749. doi:10.1111/j.1095-8649.2012.03343.x.

Jobling, M. 1994. Fish bioenergetics. Chapman \& Hall, London, UK.

Jobling, M. 2010. Are compensatory growth and catch-up growth two sides of the same coin? Aquacult. Int. 18: 501-510. doi: 10.1007/s10499-009-9260-8.

Jonsson B, and Jonsson N. 1993. Partial migration: niche shift versus sexual maturation in fishes. Rev. Fish Biol. Fish. 3: 348-365.

Jonsson, N., and Jonsson, B. 2003. Energy allocation among developmental stages, age groups, and types of Atlantic salmon (Salmo salar) spawners. Can. J. Fish. Aquat. Sci. 60(5): 506-516. doi: 10.1139/f03-042.

Jonsson, N., Jonsson, B., and Hansen, L.P. 1990. Partial segregation in the timing of migration of Atlantic salmon of different ages. Anim. Behav. 40(2): 313-321. doi: 10.1016/S0003-3472(05)80926-1.

Jonsson, N., Hansen, L.P., and Jonsson, B. 1991a. Variation in age, size and repeat spawning of adult Atlantic salmon in relation to river discharge. J. Anim. Ecol. 60(3): 937-947. Available from http://www.jstor.org/stable/5423 [accessed 3 May 2011]. 
493

494

495

496

497

498

499

500

501

502

503

504

505

506

507

508

509

510

511

512

513

514

515

Jonsson, N., Jonsson, B., and Hansen, L.P. 1991b. Energetic cost of spawning in male and female Atlantic salmon (Salmo-salar L). J. Fish Biol. 39(5): 739-744. doi: 10.1111/j.1095-8649.1991.tb04403.

Jonsson, N., Jonsson, B., and Hansen, L.P. 1997. Changes in proximate composition and estimates of energetic costs during upstream migration and spawning in Atlantic salmon Salmo salar. J. Anim. Ecol. 66(3): 425-436. Available from http://www.jstor.org/stable/5987 [accessed 3 May 2011].

Mather, M.E. 1998. The role of context-specific predation in understanding patterns exhibited by anadromous salmon. Can. J. Fish. Aquat. Sci. 55: 232-246. doi: 10.1139/d98-002.

Nagelkerke, N.J.D. 1991. A note on a general definition of the coefficient of determination. Biometrika 78(3): 691-692. doi: 10.1093/biomet/78.3.691.

Nakagawa, S., and Cuthill, I.C. 2007. Effect size, confidence interval and statistical significance: a practical guide for biologists. Biol. Rev. 82(4):591-605. doi: 10.1111/j.1469-185X.2007.00027.x.

Niemelä, E., Mäkinen, T.S., Moen, K., Hassinen, E., Erkinaro, J., Länsman, M., and Julkunen, M. 2000. Age, sex ratio and timing of the catch of kelts and ascending Atlantic salmon in the subarctic River Teno. J. Fish Biol. 56(4): 974-985. doi: 10.1006/jfbi.1999.1223.

Olsen, E.M., Knutsen, H., Simonsen, J.H., Jonsson, B., and Knutsen, J.A. 2006. Seasonal variation in marine growth of sea trout, Salmo trutta, in coastal Skagerrak. Ecol. Freshw. Fish 15(4): 446-452. doi: 10.1111/j.1095-8649.2004.00285.x.

R Development Core Team. 2009. R: A Language and Environment for Statistical Computing. R Foundation for Statistical Computing, Vienna, Austria. 
516 Rikardsen, A.H., and Dempson, J.B. 2010. Dietary life-support: the food and feeding of Atlantic salmon at sea. In Atlantic Salmon Ecology. Edited by Ø. Aas, S. Einum, A. Klemetsen and J. Skurdal. Blackwell Publishing Ltd., Oxford, UK. pp. 115-145. doi: 10.1002/9781444327755.ch5.

Schielzeth, H. 2010. Simple means to improve the interpretability of regression coefficients. Meth. Ecol. Evol. 1(2): 103-113. doi: 10.1111/j.2041-210X.2010.00012.x.

Seamons, T.R., and Quinn, T.P. 2010. Sex-specific patterns of lifetime reproductive success in single and repeat breeding steelhead trout (Oncorhynchus mykiss). Behav. Ecol. Sociobiol. 64(4): 505-513. doi: 10.1007/s00265-009-0866-7.

Thorstad, E.B., Økland, F., and Finstad, B. 2000. Effects of telemetry transmitters on swimming performance of adult Atlantic salmon. J. Fish Biol. 57(2): 531-535. doi: 10.1111/j.1095-8649.2000.tb02192.x.

Ugedal, O., Næsje, T.F., Thorstad, E.B., Forseth, T., Saksgård, L.M., and Heggberget, T.G. 2008. Twenty years of hydropower regulation in the River Alta: long-term changes in abundance of juvenile and adult Atlantic salmon. Hydrobiologia 609(1): 9-23. doi: $10.1007 / \mathrm{s} 10750-008-9404-2$.

Ward, D.M., and Hvidsten, N.A. 2010. Predation: Compensation and Context Dependence. In Atlantic Salmon Ecology. Edited by Ø. Aas, S. Einum, A. Klemetsen and J. Skurdal. Blackwell Publishing Ltd., Oxford, UK. pp. 199-220. doi: 10.1002/9781444327755.ch8.

Webb, J., Verspoor, E., Aubin-Horth, N., Romakkaniemi, A., and Amiro, P. 2007. The Atlantic salmon. In The Atlantic Salmon: Genetics, Conservation and management. Edited by E. Verspoor, L. Strandmeyer and J. Nilsen. Blackwell Publishing Ltd., Oxford, UK. pp. 17-56. 
Table 1. The number, average length, and average mass of tagged Atlantic salmon in Alta River and Fjord in 2007 - 2009, according to sex and tagging technique. Ranges (minimum-maximum) are given in parenthesis.

\begin{tabular}{|c|c|c|c|c|c|c|c|c|c|c|}
\hline & \multirow[t]{2}{*}{ Year } & \multicolumn{3}{|c|}{2007} & \multicolumn{3}{|c|}{2008} & \multicolumn{3}{|c|}{2009} \\
\hline & & $\mathbf{n}$ & Fork length $(\mathbf{c m})$ & Mass (kg) & $\mathbf{n}$ & Fork length $(\mathbf{c m})$ & Mass (kg) & n & Fork length $(\mathbf{c m})$ & Mass (kg) \\
\hline $\begin{array}{l}\text { Radio } \\
\text { tagging; }\end{array}$ & Males & - & - & - & 25 & $\begin{array}{c}98 \\
(71-122)\end{array}$ & $\begin{array}{c}11.9 \\
(3.9-23.3)\end{array}$ & 41 & $\begin{array}{c}83 \\
(54-110)\end{array}$ & $\begin{array}{c}10.1^{*} \\
(4.8-15.0)\end{array}$ \\
\hline $\begin{array}{l}\text { tagged } \\
\text { before river } \\
\text { entry }\end{array}$ & Females & - & - & - & 54 & $\begin{array}{c}96 \\
(83-116)\end{array}$ & $\begin{array}{c}11.2 \\
(6.5-17.8)\end{array}$ & 46 & $\begin{array}{c}94 \\
(82-113)\end{array}$ & $\begin{array}{c}10.0^{*} \\
(6.8-17.0)\end{array}$ \\
\hline $\begin{array}{l}\text { Acoustic } \\
\text { tagging; }\end{array}$ & Males & 27 & $\begin{array}{c}62 \\
(54-82)\end{array}$ & $\begin{array}{c}1.6 \\
(0.9-3.4)\end{array}$ & 0 & - & - & 30 & $\begin{array}{c}67 \\
(57-102)\end{array}$ & $\begin{array}{c}2.7 \\
(1.3-10.3)\end{array}$ \\
\hline $\begin{array}{l}\text { tagged } \\
\text { before river }\end{array}$ & Females & 33 & $\begin{array}{c}93 \\
(75-115)\end{array}$ & $\begin{array}{c}6.1 \\
(2.6-12.9)\end{array}$ & 73 & $\begin{array}{c}93 \\
(75-116)\end{array}$ & $\begin{array}{c}6.0 \\
(2.9-11.5)\end{array}$ & 39 & $\begin{array}{c}97 \\
(89-108)\end{array}$ & $\begin{array}{c}7.1 \\
(4.0-10.2)\end{array}$ \\
\hline exit & & & & & & & & & & \\
\hline
\end{tabular}

Note: *mass average based on 28 and 38 individuals, respectively, as data was not available for all tagged individuals 
Table 2. Probability (odds ratio with $95 \%$ confidence interval - CI) of migrating in the spring (after onset of April) rather than in the autumn (before end of January) in relation with length and body condition while controlling for year, for radio tagged Atlantic salmon $(n=84)$ in Alta River and Fjord (2007 - 2009).

\begin{tabular}{lccccc}
\hline Predictor & Odds ratio & $\mathbf{9 5 \%}$ CI & Wald & $\boldsymbol{P}$ & Model \\
& & & $\chi^{2}$ & & diagnostics* \\
\hline Intercept & 1.9 & $0.9-118.7$ & 0.9 & 0.4 & \\
Year & 5.5 & $1.3-53.0$ & 1.9 & $\mathbf{0 . 0 6}$ & $\mathrm{AUC}=0.93$ \\
Length & 29.9 & $1.0-16596.7$ & 1.5 & 0.13 & $\mathrm{R}^{2}=0.65$ \\
Condition & 265.2 & $4.32-576885.1$ & 1.7 & $\mathbf{0 . 0 8}$ & \\
\hline
\end{tabular}

Note: * The area under the receiver operating characteristic curve (AUC) and Naglekerke $\mathrm{R}^{2}$ (Nagelkerke 1991) present the predictive and explanatory power of the model, respectively. 
Table 3. Effects of sex, length and body condition, while controlling for year and tag site, on the migration timing (sea entry date) among spring migrants $(n=186)$, for Atlantic salmon tagged with acoustic transmitters in Alta River (2007-2009).

\begin{tabular}{|c|c|c|c|c|c|c|}
\hline Predictor & Level & Estimate & $95 \%$ CI & df & $\boldsymbol{F}$ & $P$ \\
\hline Intercept & & 40.9 & $33.2-48.7$ & & & \\
\hline \multirow[t]{2}{*}{ Year } & 2008 & 5.5 & $-1.8-12.9$ & 2 & 41.6 & $<0.001$ \\
\hline & 2009 & -5.8 & $-12.6-0.9$ & & & \\
\hline \multirow[t]{5}{*}{ Tag site } & 2 & -1.4 & $-9.6-6.9$ & 5 & 0.9 & 0.5 \\
\hline & 3 & -1.5 & $-7.5-4.4$ & & & \\
\hline & 4 & -1.1 & $-8.4-6.2$ & & & \\
\hline & 6 & -2.2 & $-10.1-5.6$ & & & \\
\hline & 7 & 4.0 & $-3.0-11.0$ & & & \\
\hline Sex & $\mathrm{F}$ & 4.8 & $0.1-9.4$ & 1 & 54.2 & $<0.001$ \\
\hline Condition & & 12.6 & $8.0-17.3$ & 1 & 50.6 & $<0.001$ \\
\hline Length & & 4.6 & $-2.7-11.9$ & 1 & 1.4 & 0.2 \\
\hline Sex $*$ Condition & $\mathrm{F}$ & 8.1 & $0.7-15.5$ & 1 & 7.9 & 0.005 \\
\hline Sex * Length & $\mathrm{F}$ & -8.4 & $-15.7--1.2$ & 1 & 4.6 & 0.03 \\
\hline Length $*$ Condition & & -6.2 & $-19.5-7.2$ & 1 & 0.8 & 0.4 \\
\hline
\end{tabular}

Note: $\mathrm{F}=$ female, Level $=$ category level which is associated with the estimate. $\mathrm{CI}=$ confidence interval, $\mathrm{df}=$ degrees of freedom. Model $\mathrm{R}^{2}=0.55$. 


\section{Figure captions}

Fig. 1. Map of the lower part of the Alta River and Fjord showing the position of the acoustic receiver arrays (dotted line and single dots), the stationary radio loggers (black and white squares; the white squares depicts radio loggers in use only in 2008), and the tagging sites both in the river and the fjord (stars; the black stars mark the tagging sites for radio tagged Atlantic salmon, the white stars for acoustically tagged Atlantic salmon, and the grey star an additional tagging site for radio tagged Atlantic salmon in 2009).

Fig. 2. The marine migration start of acoustically tagged kelts in 2007-2009 in Alta River in relation to water discharge, river temperature, and sea temperature. The grey vertical line marks the median migration date across all years (9 June).

Fig. 3. The probability ( \pm SE) for Atlantic salmon kelts in Alta River of migrating in autumn (0) or spring (1) in relation to body condition in 2009-2010. The thin dotted lines underline the body condition and length values where fish had a 50\% probability of migrating in spring rather than in autumn. Vertical lines on the x-axis represent the distribution of the data, i.e. each line represents a tagged male.

Fig. 4. Sea entry date (in Julian days using 1 May as day 1) of Atlantic salmon kelts in Alta River in relation to body condition (a) and fork length (b). Lines represent model predictions $( \pm \mathrm{SE})$, and dots the data. 


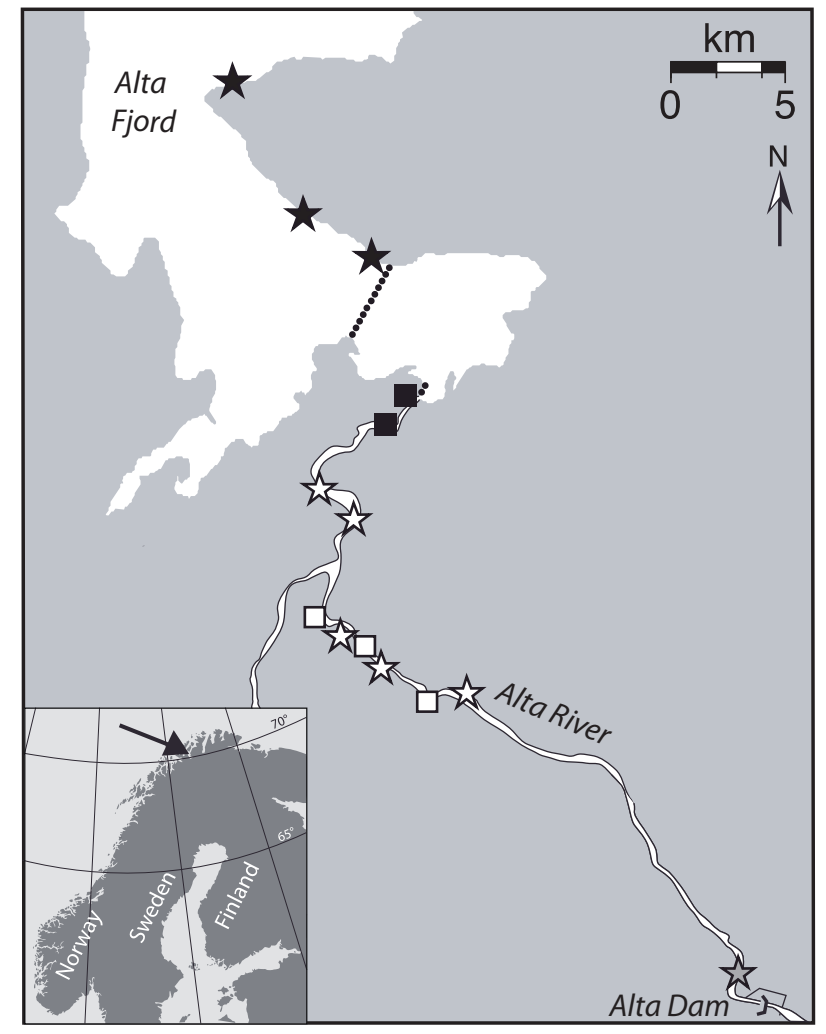




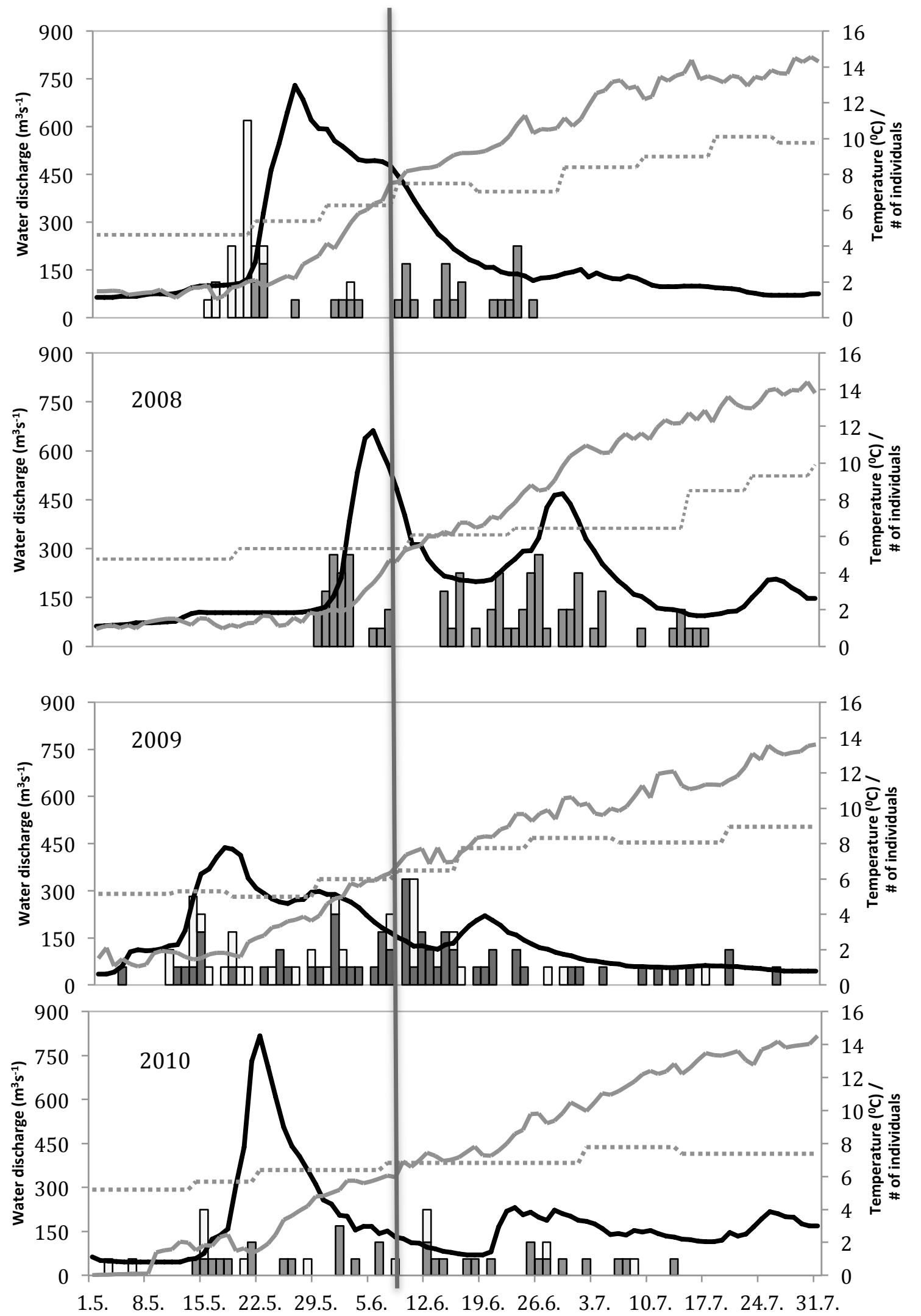

Date

$\square$ males $\square$ females $\longrightarrow$ water discharge $\longrightarrow$ river temperature " " " " " " " sea temperature 


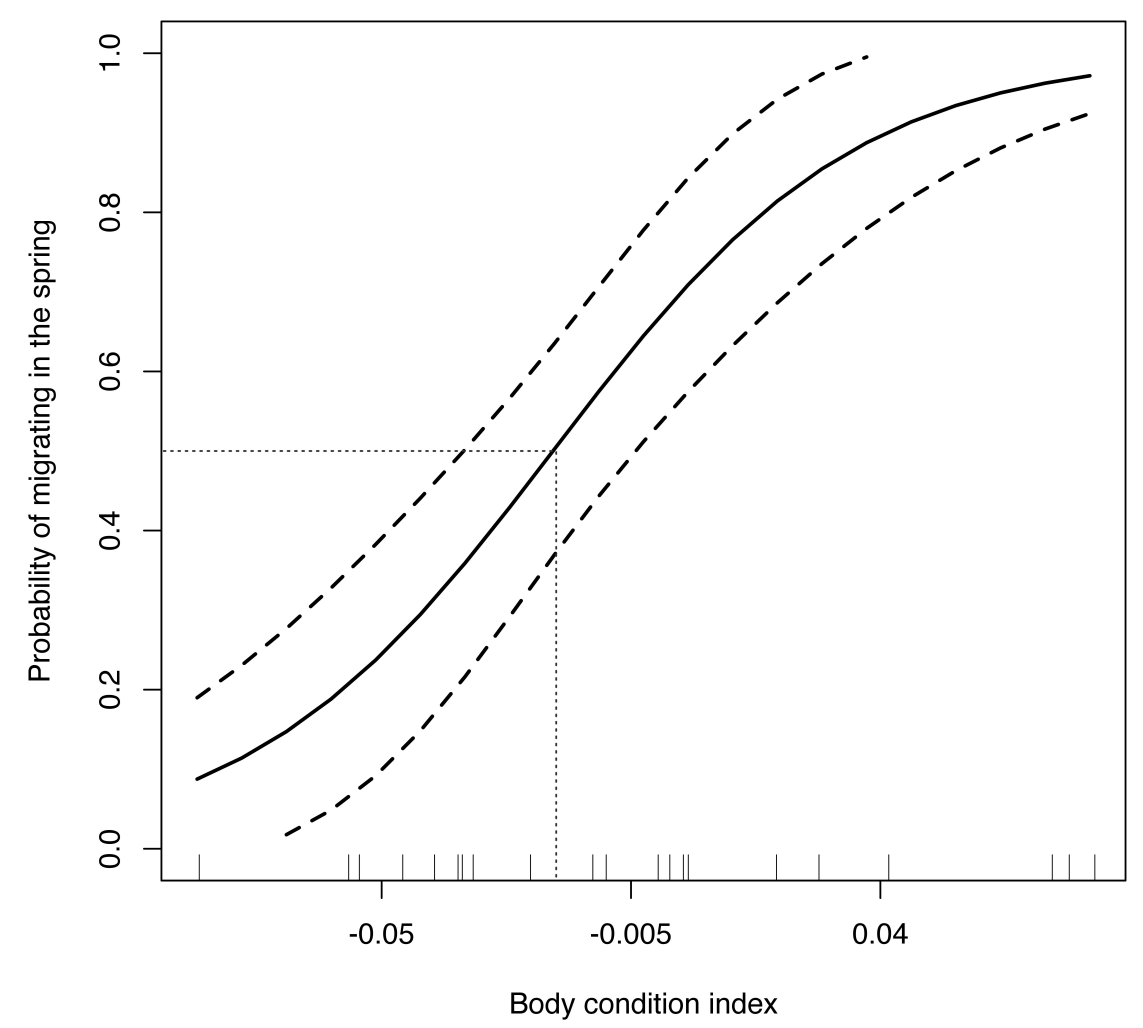

Fig. 3. The probability ( \pm SE) for Atlantic salmon kelts in Alta River of migrating in autumn (0) or spring (1) in relation to body condition in 2009-2010. The thin dotted lines underline the body condition and length values where fish had a 50\% probability of migrating in spring rather than in autumn. Vertical lines on the x-axis represent the distribution of the data, i.e. each line represents a tagged male. 


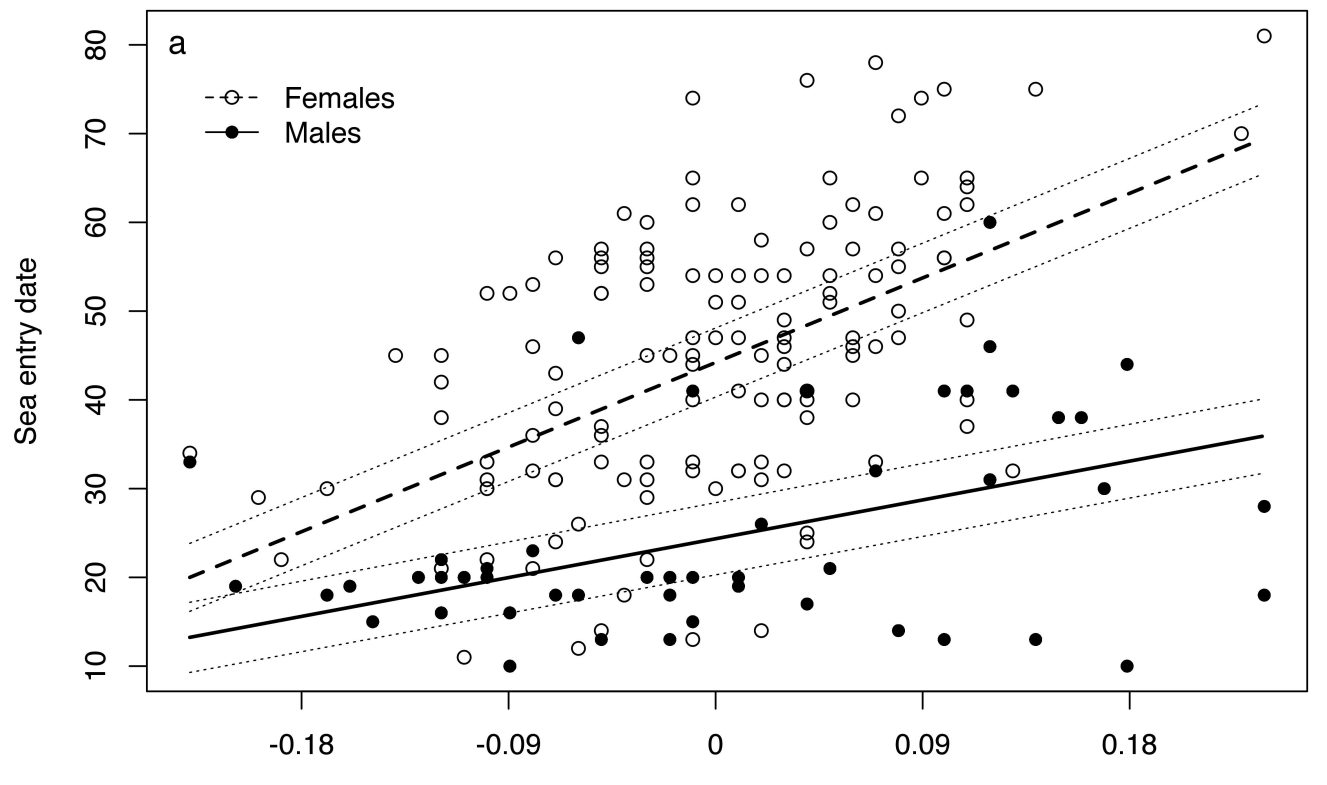

Body condition index

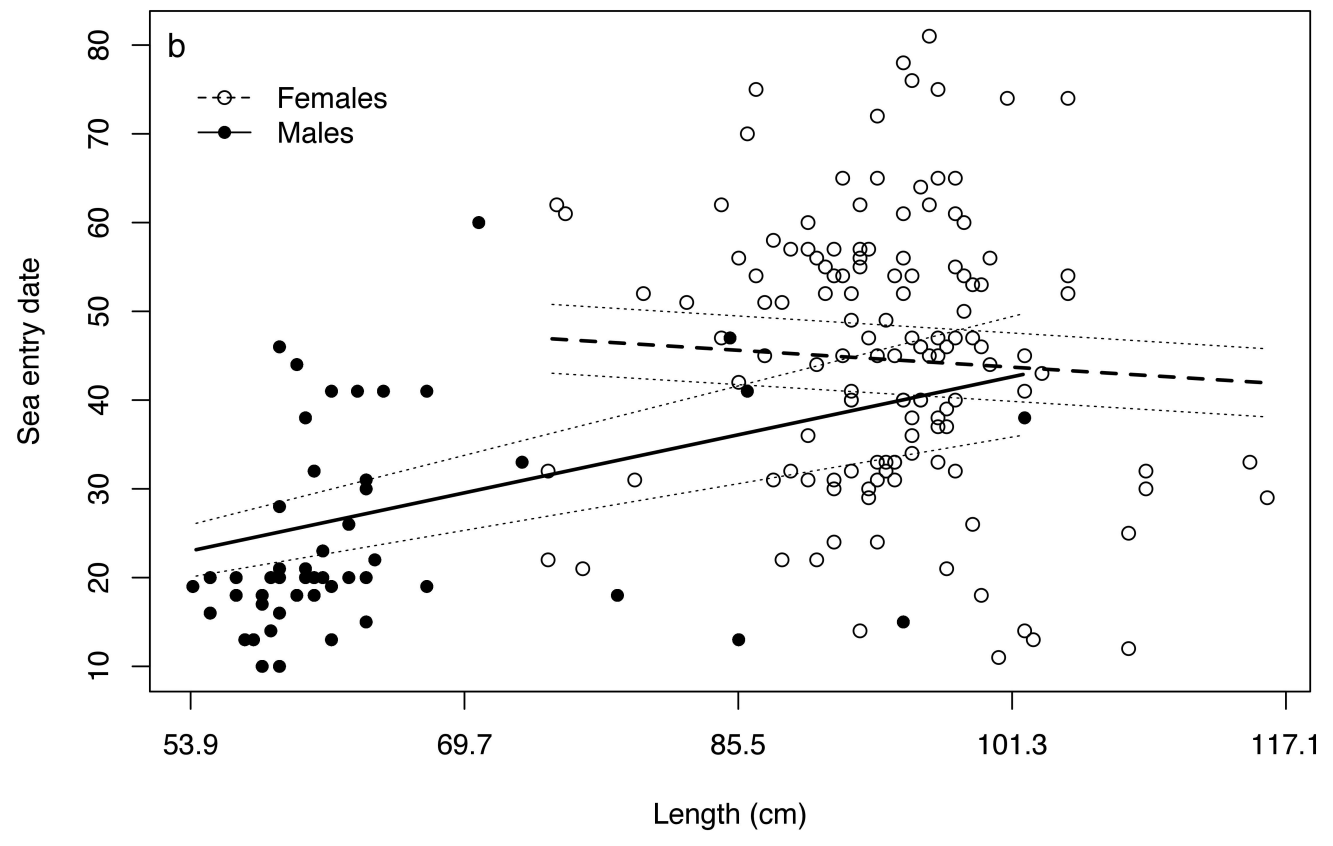

Fig. 4. Sea entry date (in Julian days using 1 May as day 1) of Atlantic salmon kelts in Alta River in relation to body condition (a) and fork length (b). Lines represent model predictions $( \pm \mathrm{SE})$, and dots the data. 